University of Nebraska - Lincoln

DigitalCommons@University of Nebraska - Lincoln

2006

\title{
Paleoclimatic Evidence for Future Ice-Sheet Instability and Rapid Sea-Level Rise
}

Jonathan T. Overpeck

University of Arizona

Bette L. Otto-Bliesner

National Center for Atmospheric Research, ottobli@ucar.edu

Gifford H. Miller

University of Colorado

Daniel R. Muhs

U.S. Geological Survey, dmuhs@usgs.gov

Richard B. Alley

Pennsylvania State University

See next page for additional authors

Follow this and additional works at: https://digitalcommons.unl.edu/usgsstaffpub

Part of the Earth Sciences Commons

Overpeck, Jonathan T.; Otto-Bliesner, Bette L.; Miller, Gifford H.; Muhs, Daniel R.; Alley, Richard B.; and Kiehl, Jeffrey T., "Paleoclimatic Evidence for Future Ice-Sheet Instability and Rapid Sea-Level Rise" (2006). USGS Staff -- Published Research. 189.

https://digitalcommons.unl.edu/usgsstaffpub/189

This Article is brought to you for free and open access by the US Geological Survey at DigitalCommons@University of Nebraska - Lincoln. It has been accepted for inclusion in USGS Staff -- Published Research by an authorized administrator of DigitalCommons@University of Nebraska - Lincoln. 
Authors

Jonathan T. Overpeck, Bette L. Otto-Bliesner, Gifford H. Miller, Daniel R. Muhs, Richard B. Alley, and Jeffrey T. Kiehl 


\section{Paleoclimatic Evidence for Future Ice-Sheet Instability and Rapid Sea-Level Rise}

\author{
Jonathan T. Overpeck, ${ }^{1 *}$ Bette L. Otto-Bliesner, ${ }^{2}$ Gifford H. Miller, ${ }^{3}$ Daniel R. Muhs, ${ }^{4}$ \\ Richard B. Alley, ${ }^{5}$ Jeffrey T. Kieht ${ }^{2}$
}

Sea-level rise from melting of polar ice sheets is one of the largest potential threats of future climate change. Polar warming by the year 2100 may reach levels similar to those of 130,000 to 127,000 years ago that were associated with sea levels several meters above modern levels; both the Greenland Ice Sheet and portions of the Antarctic Ice Sheet may be vulnerable. The record of past ice-sheet melting indicates that the rate of future melting and related sea-level rise could be faster than widely thought.

$\mathrm{M}$ illions of people and their infrastructure are concentrated near coastlines and are thus vulnerable to sea-level rise (1); entire countries may be submerged by a rise of a few meters. The Intergovernmental Panel on Climate Change (IPCC) Third Assessment (TAR) (2) suggested a rise of 0.09 to $0.88 \mathrm{~m}$ by the year 2100 unless greenhouse gas (GHG) emissions are reduced substantially. The IPCC TAR also suggested that continuing GHG emissions could trigger polar ice-cap melting beyond 2100, with sea-level rise in excess of $5 \mathrm{~m}$ within the next millennium

${ }^{1}$ Institute for the Study of Planet Earth, Department of Geosciences, and Department of Atmospheric Sciences, University of Arizona, Tucson, AZ 85721, USA. ${ }^{2}$ National Center for Atmospheric Research, Post Office Box 3000, Boulder, CO 80307, USA. ${ }^{3}$ Institute of Arctic and Alpine Research and Department of Geological Sciences, University of Colorado, Campus Box 450, Boulder, CO 80309, USA. ${ }^{4}$ U.S. Geological Survey, Mail Stop 980, Box 25046, Federal Center, Denver, CO 80225, USA. ${ }^{5}$ Department of Geosciences and Penn State Ice and Climate Exploration Center, Pennsylvania State University, 0517 Deike Building, University Park, PA 16802, USA.

*To whom correspondence should be addressed. E-mail: jto@u.arizona.edu
(2). More-recent modeling (3) indicated that the Earth will be warm enough by 2100 to melt the Greenland Ice Sheet (GIS) over the next millennium or so, and more-recent theoretical considerations (4) suggested that the melting could be faster and hence more challenging for society.

Ongoing Arctic warming is already melting ice, including sea-ice thinning and retreat and also enhanced melting of the GIS (5). These changes, coupled with recent changes in western Antarctica $(6,7)$ and the enormous potential market and nonmarket costs of large sea-level rise, led us to reexamine the climate associated with the last major sea-level rise above modern levels that occurred in Earth history. Corals on tectonically stable coasts from the last interglaciation period (LIG) provided strong evidence that sea level was 4 to $>6 \mathrm{~m}$ above present levels during a sea-level high stand that likely lasted from $129,000 \pm 1000$ years ago to at least 118,000 years ago $(8-13)$. Our goal is to untangle the causes of this past sealevel change in order to understand how sea levels may change in the next 100 years and beyond.
Recent assessments of the LIG climate and the sea-level high stand have pointed mostly to the likelihood that melting of the GIS contributed 2 or more $m$ of sea-level equivalent at that time $(14,15)$. This hypothesis is supported by the substantial orbitally driven excess of Northern Hemisphere summer insolation 130,000 years ago relative to the present day, with no corresponding Antarctic excess (Fig. 1) (16). More-recent work (17) coupled new climate and ice-sheet modeling with Arctic paleoclimatic data to make a strong case that the central part of GIS was intact throughout the LIG and that the GIS and other Arctic ice fields likely contributed 2.2 to $3.4 \mathrm{~m}$ of sea-level rise during the LIG. The low-end ( $4 \mathrm{~m}$ ) estimate of observed LIG sea-level rise can thus be explained by the high-end possible contribution from the GIS, Iceland, and other Arctic ice fields (17), plus additional small contributions from Northern Hemisphere mountain-glacier melt. However, the low to midrange estimates of LIG Arctic sea-level contribution imply at least some Antarctic contribution, and an important Antarctic contribution is required to explain a total observed LIG sea-level rise in the 4 to $>6 \mathrm{~m}$ range.

Recent thinning along the margins of the East Antarctic Ice Sheet (EAIS) and, in particular, over notable portions of the West Antarctic Ice Sheet (WAIS) (18-20) suggests there may have been LIG contributions to sea level from both parts of the Antarctic Ice Sheet. There has been longstanding concern regarding the potential for rapid WAIS collapse and the $\leq 5$-m sea-level rise that might follow warminginduced loss of buttressing ice shelves (21). That concern was downplayed subsequently but has reemerged because warming-induced iceshelf reduction along the Antarctic Peninsula and in the Amundsen Sea region was followed by accelerated flow of tributary glaciers $(6,7,20)$. Although state-of-the-art knowledge of ice sheet dynamics may not be sufficient to simulate cur- 
rent or future changes in the WAIS $(6,20)$, our inference that the Antarctic Ice Sheet likely contributed to sea-level rise during the LIG indicates that it could do the same if the Earth's climate warms sufficiently in the future.

Although the low-end $(\leq 4 \mathrm{~m})$ estimates of the observed LIG sea-level high stand may not require a substantial contribution from the Antarctic Ice Sheet, there are two lines of evidence that support a WAIS contribution (in addition to the evidence that LIG sea level may have been substantially more than $4 \mathrm{~m}$ above present). First, diatom and ${ }^{10} \mathrm{Be}$ data collected from sediments below the ice-stream region of the Ross Embayment indicate that the central WAIS was likely smaller at some point in the last several hundred thousand years (22), and it now appears that the LIG, not an earlier interglaciation [i.e., marine isotope stage 11, circa (ca.) 400,000 years ago (23)], is the most likely candidate for an associated sea-level rise of the needed magnitude. Second is the evidence from multiple ice cores (24-26) that some process caused substantial $\left(2.5^{\circ}\right.$ to over $\left.5^{\circ} \mathrm{C}\right)$ warming over East Antarctica beginning at the same early LIG time as the observed sea-level high stand [as suggested by the coincidence of the peak isotope-inferred LIG warming and $\mathrm{CH}_{4}$ levels (26)]. This is surprising given the lack of a positive summertime south polar insolation anomaly (Fig. 1) and simulated (27) LIG cooling over Antarctica (Fig. 2). A possible explanation is the presence of a much-reduced WAIS that would have lowered albedo and altered atmospheric circulation over a large area of Antarctica. These changes could have driven the observed warmer temperatures over the Antarctic region in Southern Hemisphere summer.

Assuming that the GIS and WAIS both may have contributed to the LIG sea-level high stand, we used a state-of-the-art coupled atmosphereocean climate model to simulate the climate of 130,000 years ago and then compared this simulation with simulations of the next 140 years made with the same model to learn how much sea-level rise might be expected in the future (27). Results of our LIG climate simulation are in good agreement with observed Northern Hemisphere warming for the LIG (17) and reveal several key aspects of the LIG climate (Fig. 2). First, the simulated LIG was warmer than the present period in the Northern Hemisphere but not in the Southern, consistent with strong northern but near-zero southern summer insolation anomalies at that time (Fig. 1). This result indicates that sea-level rise at 130,000 to 128,000 years ago probably started first with the melting of the GIS and not the Antarctic Ice Sheet. Simulated summertime LIG warming of Greenland is less than $5^{\circ} \mathrm{C}$ everywhere and averages less than $3.5^{\circ} \mathrm{C}$ above modern temperatures (Fig. 2), providing our estimate of the warmth needed to cause the shrinkage of GIS that occurred during the

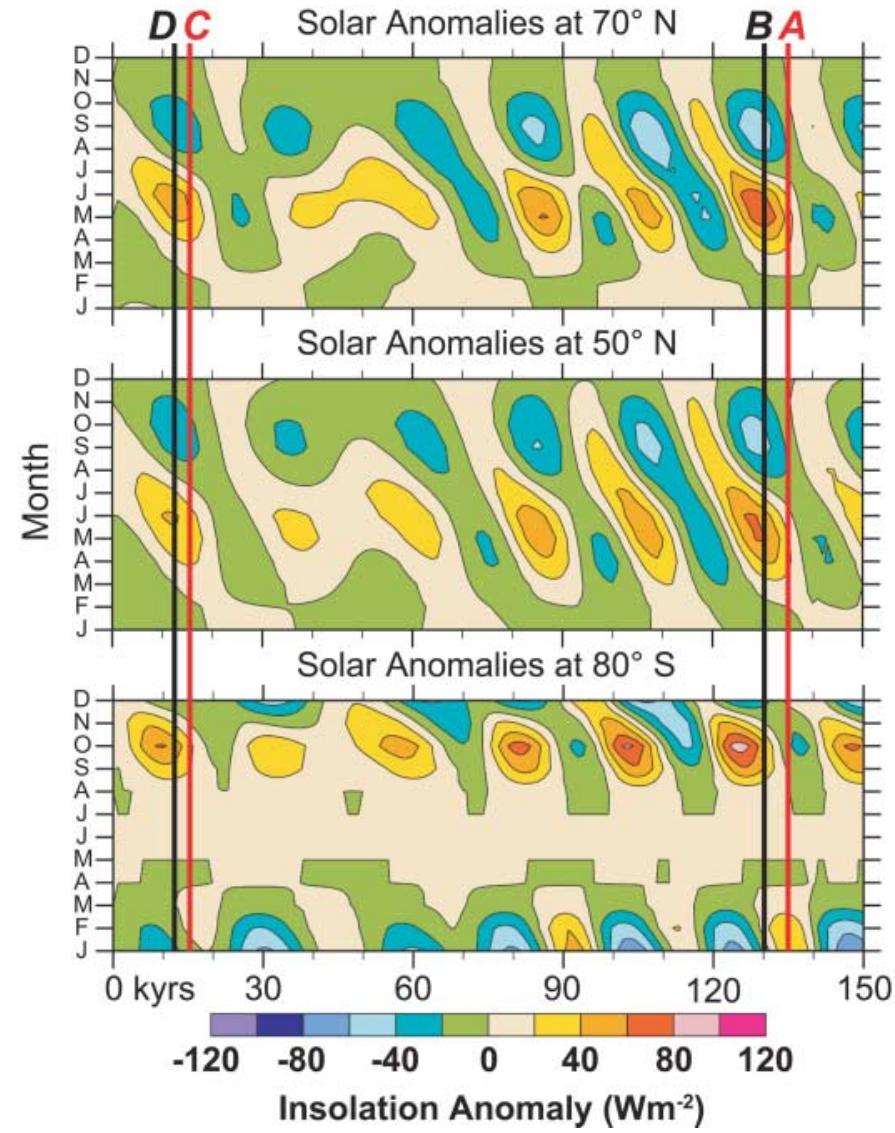

Fig. 1. Comparison of insolation anomalies (16) over the past 150,000 years for $70^{\circ} \mathrm{N}$ (top), $50^{\circ} \mathrm{N}$ (middle), and $80^{\circ} \mathrm{S}$ (bottom). Insolation sufficient to begin major melting leading to the last interglaciation occurred only after ca. 135,000 years ago (line labeled " $A$ "); an inference based on the observation that major melting over the more well-constrained and recent deglaciation did not begin until the same level of insolation was reached at ca. 15,000 years ago (30) (line labeled " $C$ "). A much higher rate of Northern Hemisphere summertime insolation increase existed over the penultimate deglaciation (line labeled " $\mathrm{B}$," ca. 130,000 years ago) than over the most recent deglaciation (line labeled "D," ca. 12,000 years ago).

LIG. These temperatures were associated with a simulated net annual reduction in snowfall over Greenland (Fig. 2). Simulated summer sea ice in the Arctic Ocean was greatly reduced at ca. 130,000 years ago, in accord with the paleoenvironmental record from this region [references in (17)]. Lastly, because of the latitudinally asymmetric insolation anomalies during the LIG, simulated annual average global temperature was not notably warmer than present, implying that sea-level rise due to ocean expansion at that time was likely minimal.

Comparison of the summer-season warmth sufficient to have melted much of the GIS 130,000 years ago with simulated future climate (Fig. 2) indicates that at (or before) 2100 A.D. (and three times the amount of preindustrial $\mathrm{CO}_{2}$ ), the high northern latitudes around Greenland will be as warm as or warmer than they were 130,000 years ago and hence warm enough to melt at least the large portions of the GIS that apparently melted during the LIG (17). This finding assumes that GHG concentrations will rise at a rate equivalent to $1 \%$ per year through the end of this century; slowed increases would delay the ice-sheet response, and faster increases would accelerate the response. As with our paleoclimate LIG simulation, it does not appear likely that increased snowfall (Fig. 2) or ocean circulation changes (17) will offset GIS melting.
Recent assessment of future climate change (2) indicates that the amount of future warming is highly dependent on the model used, with some models less sensitive to elevated atmospheric GHG concentrations than others. The model we used has midrange sensitivity and appears reasonably accurate (27). Both past and future simulations are characterized by large Arctic warmings (i.e., to above freezing) that extend from the spring into the fall. The future susceptibility of the GIS to melting is also likely to be exacerbated by soot-induced snow aging (28), a factor that probably did not play a role 130,000 years ago. Lastly, Greenland could be much warmer by 2130 than it was during the LIG (Fig. 2), assuming a 1\% per year increase in $\mathrm{CO}_{2}$ or equivalent GHGs. Thus, by any account the GIS could be even more susceptible to melting in the near future than it was 130,000 years ago.

Recent rates of sea-level rise $(2.6 \pm 0.04 \mathrm{~mm} /$ year) (29) are already nearing the maximum average rate $(3.5 \mathrm{~mm} /$ year $)$ projected to occur over the next 1000 years by the IPCC (2). This anticipated rate is substantially less than the $11 \mathrm{~mm} /$ year average rate of sea-level rise measured for the last deglaciation between 13,800 and 7000 years ago (30). As mentioned earlier, however, the penultimate deglaciation, culminating with the LIG sea-level high stand 4 to $>6 \mathrm{~m}$ above that of the present day, was driven by a substantially larger northern high 

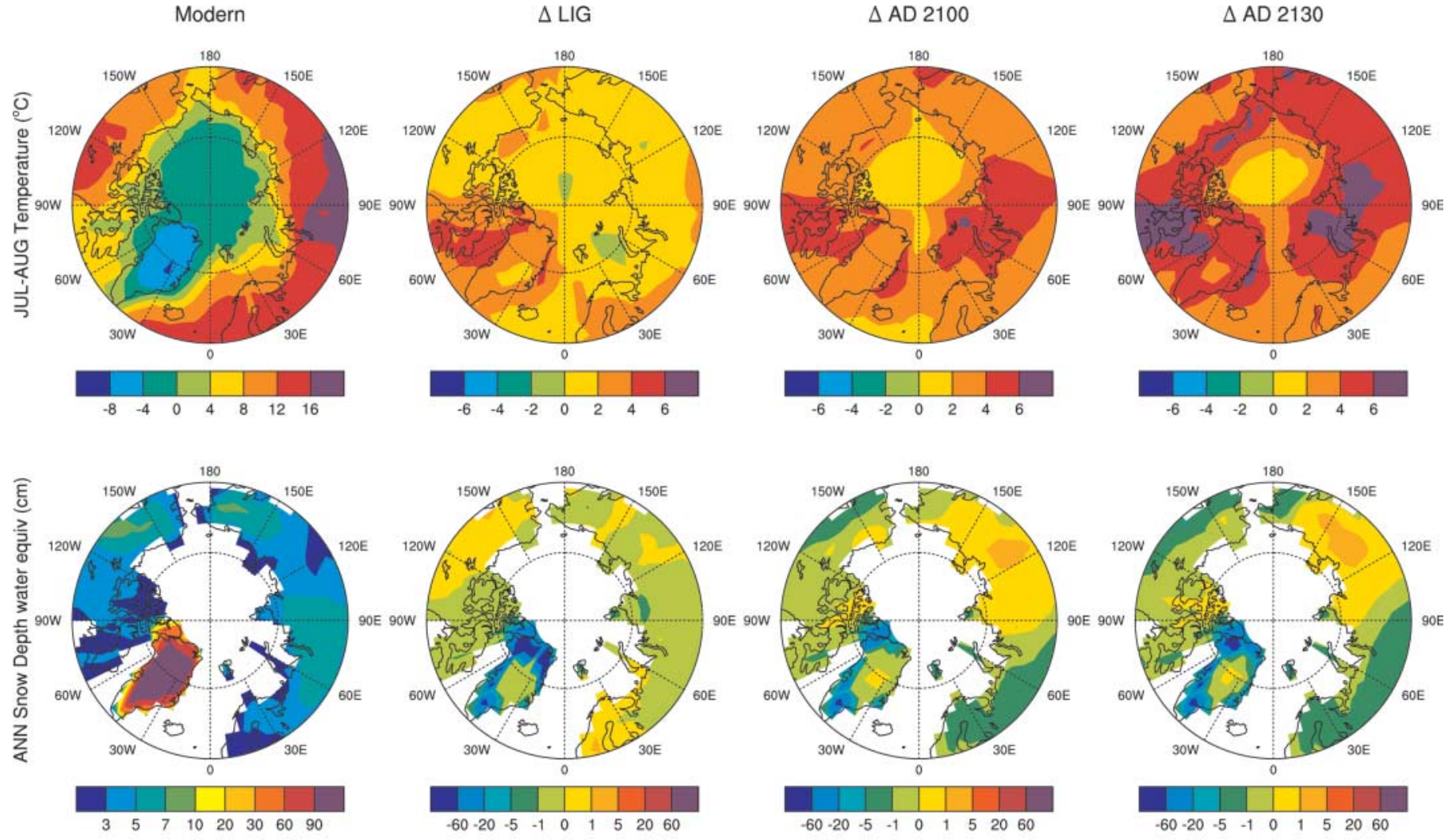

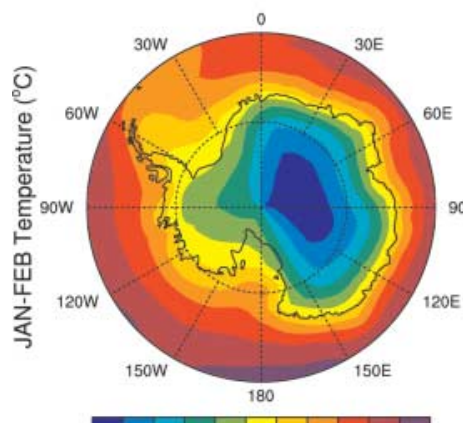

$-28-24-20-16-12-8 \quad-4 \quad 0 \quad 4 \quad 8$

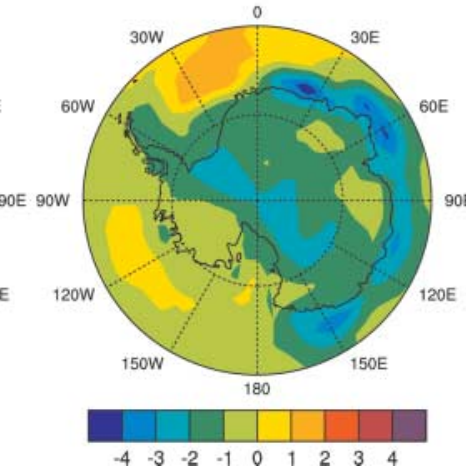

$\begin{array}{lllllllll}4 & -3 & -2 & -1 & 0 & 1 & 2 & 3 & 4\end{array}$

Fig. 2. Simulated climate for each of four time periods, from left to right: present day (Modern), 130,000 years ago (anomalies from present day, $\Delta$ LIG), 2100 A.D. (the time atmosphere reaches three times preindustrial $\mathrm{CO}_{2}$ levels, climate anomalies from present day, $\triangle$ AD 2100), and 2130 A.D. (four times preindustrial $\mathrm{CO}_{2}$ levels,
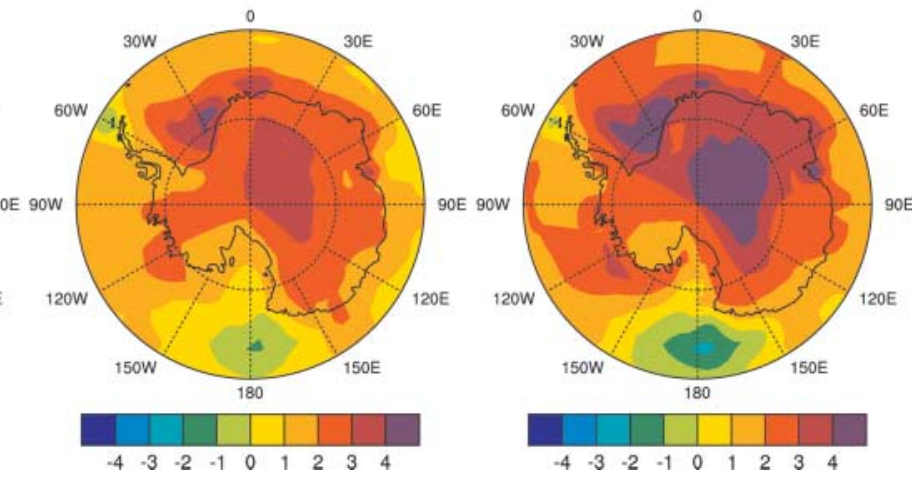

climate anomalies from present day, $\triangle A D$ 2130). Shown for each time period are peak summertime (July to August and January to February means) surface air temperature and annual snow depth. Note significant warming at north polar latitudes and the lack of any summer warming over Antarctic at 130,000 years ago. latitude summertime insolation anomaly (Fig. 1). It seems likely, therefore, that ice-sheet melting leading to the LIG sea-level rise should have been at least as fast as the sea-level rise $(11 \mathrm{~mm} /$ year) associated with the close of the last glacial period. Although a well-constrained record of sea-level rise leading to the LIG high stand is not yet available, there is well-dated yet controversial coral evidence that sea-level rise over this interval may have occurred at rates higher than $20 \mathrm{~mm}$ /year, perhaps right up to the LIG sea-level high stand (31). This makes sense given the much higher insolation (and warming) anomaly at this time and also the very real possibility that a LIG shrinkage of the WAIS (21) may be required to explain the large amount of sea-level rise above that of the present day at that time. Other recent paleo-sea-level studies indicate that very rapid sea-level rise is indeed possible (32).

Our analysis, as well as ongoing changes in coastal Antarctica, are at least suggestive that the WAIS can indeed shrink rapidly as originally envisioned by Mercer (21). Given that there was no positive summer (melt-season) insolation anomaly at high southern latitudes in the several millennia before 129,000 years ago, it appears that two factors may have led to a LIG collapse of the WAIS (or perhaps portions of the EAIS). The first may have been the sealevel rise associated with pre-129,000 to
128,000 years ago GIS melting, and the second factor may have been shallow ocean warming around and under the Antarctic ice shelves that buttress portions of the Antarctic Ice Sheet. Sea-level rise seems to have had minor effects on the WAIS during the most recent deglaciation (33), but perhaps the greater speed of sea-level rise into the LIG compared with that from the Last Glacial Maximum (ca. 21,000 years ago) played a role by reducing the ability of isostatic rebound after groundingline retreat to shallow sub-ice-shelf cavities and promote regrounding. As for the subsurface warming of south polar oceans, our LIG simulation showed modest (generally less than $0.5^{\circ}$ but up to $1^{\circ} \mathrm{C}$ ) warming in the 
Fig. 3. Simulated shallow (100 m, top; $200 \mathrm{~m}$, bottom) annual mean ocean potential temperatures for each of four time periods, from left to right: present day, 130,000 years ago (anomalies from present day), 2100 A.D. (time atmosphere reaches three times preindustrial $\mathrm{CO}_{2}$ levels, climate anomalies from present day), and 2130 A.D. (four times preindustrial $\mathrm{CO}_{2}$ levels, climate anomalies from present day). A ca. 2month-long positive insolation anomaly in austral spring (Fig. 1) fails to warm surface air temperatures over Antarctica to above freezing but
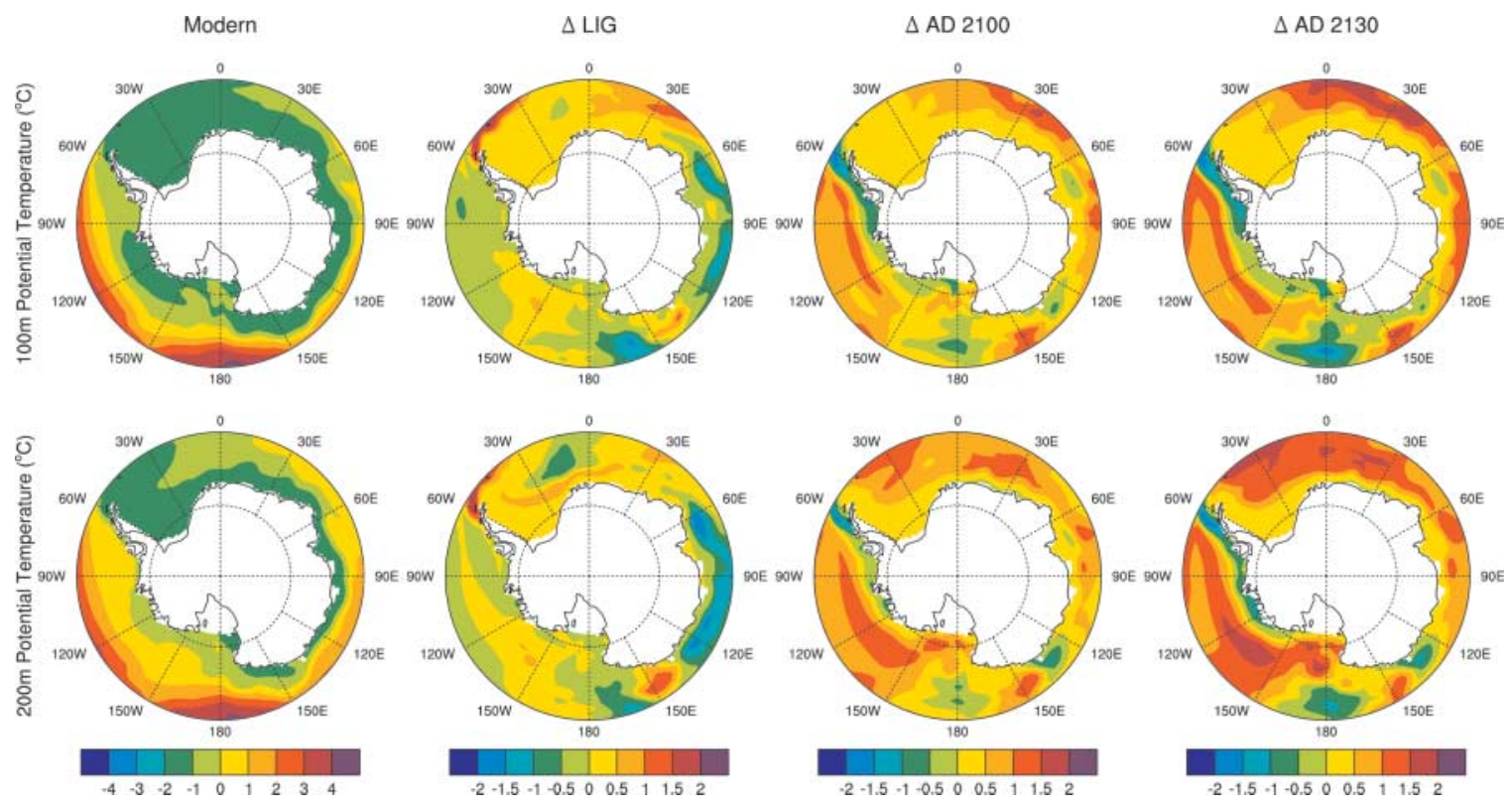

nonetheless acts to warm the subsurface shallow ocean, as well as ice shelves of the same depth.

upper $200 \mathrm{~m}$ of the ocean (Fig. 3) that would have further weakened ice shelves by thinning them from below; Shepherd et al. (34) find that such a modest warming increases subice-shelf melt rates substantially, by perhaps $5 \mathrm{~m} /$ year up to $10 \mathrm{~m} /$ year. In our simulation, this small but notable warming was due to a positive springtime (October) insolation anomaly driving reduced sea ice and enhanced subsurface warming; note that this cool-season warming was not large enough to generate positive surface air temperature anomalies over the Antarctic in summer (Fig. $2)$. Even more dramatic ocean warming is likely in the future (Fig. 3), along with surface air temperature increases (in all seasons) and continued sea-level rise that could destabilize ice shelves that buttress the Antarctic Ice Sheet. Heat transport beneath ice shelves is highly complex, so caution is required, but the LIG may provide a conservative constraint on the future dynamics of the Antarctic Ice Sheet and particularly the WAIS. Moreover, the same parts of the Antarctic Ice Sheet may prove vulnerable even given increased precipitation [e.g., (35)].

The ice-sheet origin of the LIG sea-level high stand in response to relatively small warming, together with recent results showing rapid response of ice to warming [e.g., $(36,37)]$, pose important challenges for ice-sheet modeling; whole ice sheet models do not yet incorporate important physical processes implicated in these changes $(6,20)$. Even in the absence of more-realistic models of ice-sheet behavior, it remains that ice sheets have contributed meters above modern sea level in response to modest warming, with peak rates of sea-level rise possibly exceeding $1 \mathrm{~m} /$ century. Current knowledge cannot rule out a return to such conditions in response to continued GHG emissions. Moreover, a threshold triggering many meters of sea-level rise could be crossed well before the end of this century, particularly given that high levels of anthropogenic soot may hasten future ice-sheet melting (28), the Antarctic could warm much more than 129,000 years ago (Figs. 2 and 3), and future warming will continue for decades and persist for centuries even after the forcing is stabilized $(38,39)$.

\section{References and Notes}

1. R. J. Nicholls, Global Environ. Change 14, 69 (2004).

2. IPCC, Ed., Climate Change 2001: The Scientific Basis. Contribution of Working Group I to the Third Assessment Report of the Intergovernmental Panel on Climate Change (Cambridge Univ. Press, Cambridge, 2001), p. 881.

3. J. M. Gregory, P. Huybrechts, S. C. B. Raper, Nature $\mathbf{4 2 8 ,}$ 616 (2004).

4. J. E. Hansen, Clim. Change 68, 269 (2005).

5. Arctic Climate Impact Assessment, Impacts of a Warming Arctic: Arctic Climate Impact Assessment (Cambridge Univ. Press, Cambridge, 2004), pp. 184-242.

6. M. Oppenheimer, R. B. Alley, Clim. Change 64, 1 (2004).

7. A. J. Cook, A. J. Fox, D. G. Vaughan, J. G. Ferrigno, Science 308, 541 (2005).

8. J. H. Chen, H. A. Curran, B. White, G. J. Wasserburg, Geol. Soc. Am. Bull. 103, 82 (1991).

9. C. H. Stirling, T. M. Esat, M. T. McCulloch, K. Lambeck, Earth Planet. Sci. Lett. 135, 115 (1995).

10. C. H. Stirling, T. M. Esat, K. Lambeck, M. T. McCulloch, Earth Planet. Sci. Lett. 160, 745 (1998).

11. C. Israelson, B. Wohlfarth, Quat. Res. 51, 306 (1999).

12. C. Fruijtier, T. Elliott, W. Schlager, Geol. Soc. Am. Bull. 112,267 (2000).

13. D. R. Muhs, K. R. Simmons, B. Steinke, Quat. Sci. Rev. 21, 1355 (2002).

14. K. Cuffey, S. Marshall, Nature 404, 591 (2000).

15. L. Tarasov, W. R. Peltier, J. Geophys. Res. 108, 10.1029/ 2001]B001731 (2003).

16. A. L. Berger, Quat. Res. 9, 139 (1978).

17. B. L. Otto-Bliesner et al., Science 311, 1751 (2006).

18. E. Domack et al., Nature 436, 681 (2005).
19. C. H. Davis, Y. H. Li, J. R. McConnell, M. M. Frey, E. Hanna, Science 308, 1898 (2005); published online 19 May 2005 (10.1126/science.1110662).

20. R. B. Alley, P. U. Clark, P. Huybrechts, I. Joughin, Science 310, 456 (2005).

21. J. H. Mercer, Nature 271, 321 (1978).

22. R. P. Scherer et al., Science 281, 82 (1998).

23. A. W. Droxler, R. Z. Poore, L. H. Burckle, Eds., AGU Monogr. 137, 240 (2003).

24. J. Jouzel et al., J. Geophys. Res. 108, 10.1029/ 2002JD002677 (2003).

25. O. Watanabe et al., Nature 422, 509 (2003).

26. L. Augustin et al., Nature 429, 623 (2004).

27. Materials and methods are available as supporting material on Science Online.

28. ]. Hansen, L. Nazarenko, Proc. Natl. Acad. Sci. U.S.A. 101, 423 (2004).

29. A. Cazenave, R. S. Nerem, Rev. Geophys. 42, 10.1029/ 2003RG000139 (2004).

30. E. Bard et al., Nature 382, 241 (1996).

31. M. T. McCulloch, T. Esat, Chem. Geol. 169, 107 (2000).

32. W. G. Thompson, S. L. Goldstein, Science 308, 401 (2005).

33. H. Conway, B. L. Hall, G. H. Denton, A. M. Gades, E. D. Waddington, Science 286, 280 (1999).

34. A. Shepherd, D. Wingham, E. Rignot, Geophys. Res. Lett. 31, 10.1029/2004GL021106 (2004).

35. P. Huybrechts, ]. Gregory, I. Janssens, M. Wild, Global Planet. Change 42, 83 (2004).

36. H. J. Zwally et al., Science 297, 218 (2002); published online 6 June 2002 (10.1126/science.1072708).

37. T. A. Scambos, J. A. Bohlander, C. A. Shuman, P. Skvarca, Geophys. Res. Lett. 31, 10.1029/2004GL020670 (2004).

38. G. A. Meehl et al., Science 307, 1769 (2005)

39. T. M. L. Wigley, Science 307, 1766 (2005).

40. We thank T. Ager, P. Anderson, ]. Brigham-Grette, J. Chappell, T. Crowley, L. Edwards, M. Edwards, J. Gregory, V. Masson-Delmotte, ]. Jouzel, M. Oppenheimer, W. R. Peltier, D. Raynaud, and R. Thompson for helpful discussions; numerous reviewers for excellent suggestions; and the NSF for funding support.

\section{Supporting Online Material}

www.sciencemag.org/cgi/content/full/311/5768/1747/DC1 Materials and Methods

Fig. S1

23 May 2005; accepted 2 March 2006

10.1126/science. 1115159 


\section{Supporting Online Material for:}

"Paleoclimatic Evidence for Future Ice Sheet Instability and Rapid Sea Level Rise"

Jonathan T. Overpeck $^{1 *}$

Bette L. Otto-Bliesner ${ }^{2}$

Gifford H. Miller ${ }^{3}$

Daniel R. Muhs ${ }^{4}$

Richard Alley ${ }^{5}$

Jeffrey T. Kiehl ${ }^{6}$

${ }^{1}$ Institute for the Study of Planet Earth, Department of Geosciences, and Department of Atmospheric Sciences, University of Arizona, Tucson, Arizona 85721, USA

${ }^{2}$ National Center for Atmospheric Research, P.O. Box 3000, Boulder, Colorado 80307, USA; ottobli@ncar.ucar.edu

${ }^{3}$ Institute of Arctic and Alpine Research and Department of Geological Sciences, University of Colorado, Campus Box 450, Boulder, CO 80309, USA; gmiller@,Colorado.edu

${ }^{4}$ U.S. Geological Survey, M.S. 980, Box 25046, Federal Center, Denver, Colorado 80225, USA; dmuhs@usgs.gov

${ }^{5}$ Department of Geosciences, Pennsylvania State University, 0517 Deike Bldg., University Park, PA 16802, USA; rba6@psu.edu

${ }^{6}$ National Center for Atmospheric Research, P.O. Box 3000, Boulder, Colorado 80307, USA; jtkon@ucar.edu

*To whom correspondence should be addressed.

E-mail: jto@u.arizona.edu 


\section{Climate Modeling Methods}

The model is the National Center for Atmospheric Research Community Climate System Model [CCSM], Version 2) (S1). CCSM2 includes an atmospheric model at a resolution of 3.75 degrees latitude and longitude and 26 vertical levels, an ocean model with 320x384 grid points and 40 levels, a sea ice model that includes both thermodynamics and elastic-viscous-plastic dynamics, and a land model that includes explicit river runoff and the physical effects of vegetation and land ice. Vegetation and land-ice coverage for both simulations were prescribed at their present-day distributions. In accordance with what is known about climate forcing at the peak of the LIG, we prescribed our experimental forcing to be the same as 1990 with the exception that seasonal insolation $\left((S 2, S 3)\right.$; e.g., Fig. 1) and atmospheric greenhouse levels $\left(\mathrm{CO}_{2}=280\right.$ ppmv, $\mathrm{CH}_{4}=600$ ppbv; $(S 3))$ were set to be the same as 130,000 years ago. Although peak northern highlatitude warmth of the LIG could have occurred 1000 to 2000 years after 130,000 yr B.P., the forcing would not have been significantly different from that we prescribed. We used the same model to simulate climate into the future, setting atmospheric $\mathrm{CO}_{2}$ to increase $1 \%$ per year from 1990 values of 355 ppmv. We note that this commonly-used estimate of future $\mathrm{CO}_{2}$ increase (as a proxy for the combined increases of $\mathrm{CO}_{2}, \mathrm{CH}_{4}, \mathrm{~N}_{2} \mathrm{O}$ and other increasing greenhouse gases) is well within the range of plausible future greenhouse gas increase scenarios estimate by the IPCC $(S 4)$. Of course, the time it takes the atmosphere to reach given levels of greenhouse gas concentration depends on human decisions regarding the rates of future greenhouse gas emissions. For example, it is highly likely that the ice sheet changes described in this paper could be avoided if humans were to significantly reduce emissions early in the current century. 


\section{Notes on Model Realism}

A companion paper (S3) contains the evidence confirming that the CCSM2 model is able to simulate both realistic modern day climate fields, as well as realistic climate change. In particular, Otto-Bliesner et al. (S3) show that the CCSM2 is able to simulate a realistic northern hemisphere response to Last Interglacial (LIG) climate forcing. Here, we expand on Otto-Bliesner et al., to confirm the model's ability to simulate southern hemisphere climate.

The CCSM2 simulation of Southern Hemisphere climate is realistic and improved as compared to that of the previous version of the model, CSM1 $(S 1)$. The transport through the Drake Passage at a rate of $120 \mathrm{~Sv}$ is well simulated. Sea ice off Antarctica extends very thin ice too far north in the Atlantic sector of the Southern Ocean in CCSM2, resulting in an average areal coverage that is too large, although the amplitude of the simulated annual cycle of Antarctic sea ice is realistic.

CCSM2 does a reasonable job reproducing the ocean potential temperatures in the top $200 \mathrm{~m}$ around Antarctica as compared to the data of Levitus (S5; Fig. S1). At 100 and $200 \mathrm{~m}, \mathrm{CCSM} 2$ is too warm at $\sim 60^{\circ} \mathrm{S}$ in the Pacific-Indian sector of the Southern Ocean because of a poleward shift and a more diffuse polar front. In the Atlantic sector, the top $200 \mathrm{~m}$ of the Southern Ocean at $\sim 60^{\circ} \mathrm{S}$ is too cold in association with a more northward path of the Antarctic Circumpolar Current. The ocean temperatures just adjacent to the West Antarctic Ice Sheet (WAIS) are simulated well as compared to the data, generally 
within $1^{\circ} \mathrm{C}$ of Levitus. In addition, the rate of ocean heat uptake down to $300 \mathrm{~m}$ in CCSM2 compares favorably to the observed 40-year trend (S6, S7). 

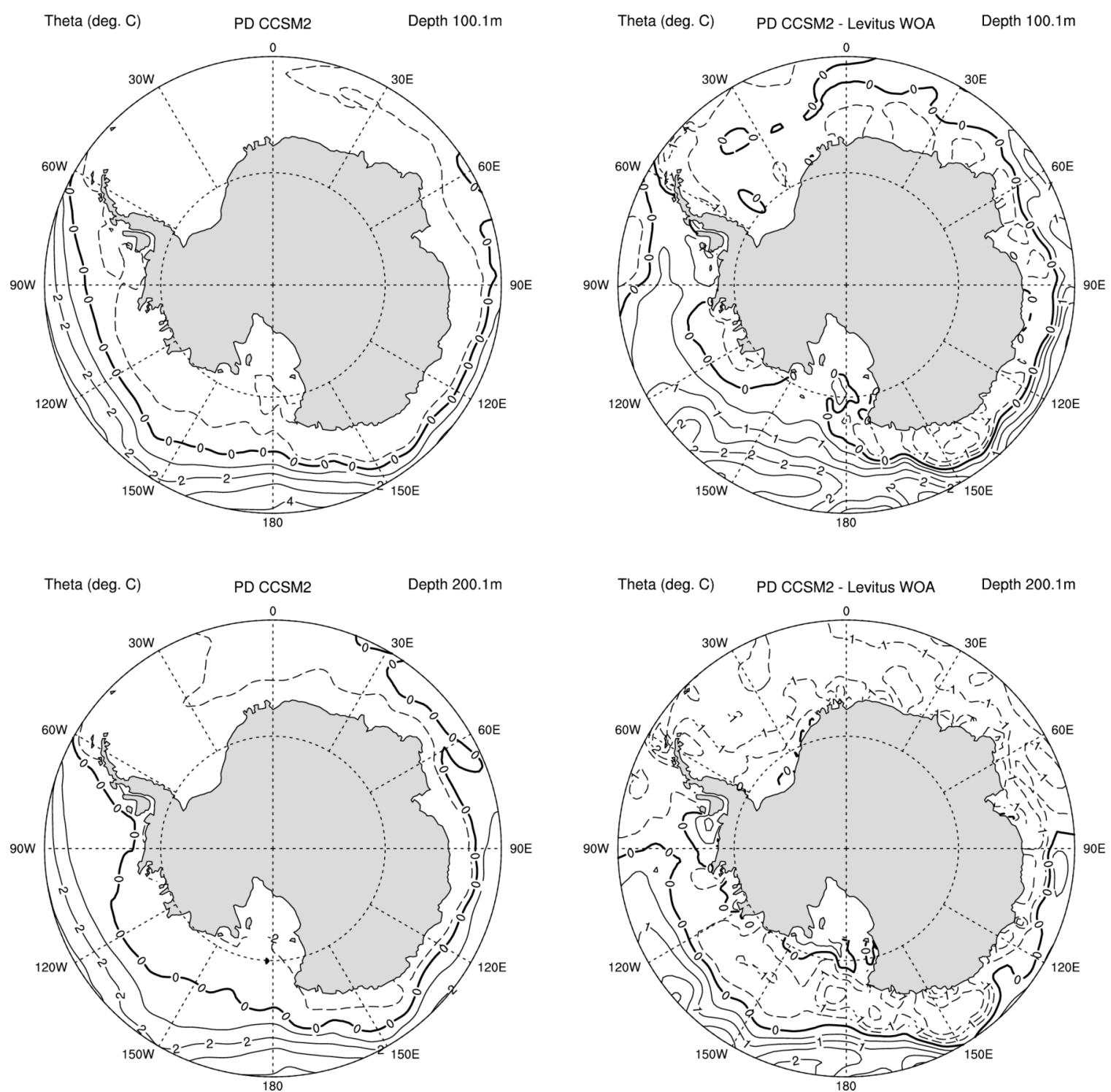

Figure S1. Southern Ocean potential temperature $\left({ }^{\circ} \mathrm{C}\right)$ at $100 \mathrm{~m}$ depth (top) and $200 \mathrm{~m}$ depth (bottom) as simulated for present-day by CCSM2 (left) and as compared to World Ocean Atlas data (right) of Levitus (S5). 


\section{Supplementary References}

S1. J. T. Kiehl, P. R. Gent, Journal of Climate 17, 3666 (2004).

S2. A. L. Berger, Quaternary Research 9, 139 (1978).

S3. B. L. Otto-Bliesner et al., Science (submitted).

S4. IPCC, Ed., Climate Change 2001: The Scientific Basis. Contribution of Working Group I to the Third Assessment Report of the Intergovernmental Panel on Climate Change (Cambridge University Press, Cambridge, 2001), pp. 881.

S5. S. Levitus, T. P. Boyer, in World Ocean Atlas 1994. (National Oceanic and Atmospheric Administration, 1994) pp. 117 pp.

S6. $\quad$ S. Levitus, J. I. Antonov, T. P. Boyer, C. Stephens, Science 287 (2000).

S7. $\quad$ P. R. Gent, G. Danabasoglu, Journal of Climate 17, 4058 (2004). 